\title{
KINEMATIC DESIGN OF LIFT-TIPPING MECHANISM FOR SMALL SOLID WASTE COLLECTION TRUCK
}

\author{
Y.A.K. Fiagbe., ${ }^{1}$ M. N. Sackey ${ }^{1}$, M.Y. Mensah., ${ }^{2}$ and E.E.K. Agbeko ${ }^{1}$ \\ ${ }^{l}$ Department of Mechanical Engineering, KNUST, Kumasi, Ghana \\ ${ }^{2}$ Department of Chemical Engineering, KNUST, Kumasi, Ghana
}

\begin{abstract}
A number of small waste collection trucks such as tricycles are in use in a number of developing countries. The use of such technology has been popular in a country like Ghana. This paper presents a design of lift-tipping mechanism for small solid waste collection trucks. A five bar mechanism is developed with one degree of freedom. The mechanism is modelled and tested using Solid Edge software. Results of the system show that a height of $70 \%$ of the length of the lifting bar can be attained and a tilt angle more than $40^{\circ}$ could be achieved. The actuation of the mechanism could be achieved by employing power screw, hydraulic or pneumatic actuators, and rack and pinion combinations. This mechanism will improve the operation of the collection truck.
\end{abstract}

Keywords: Lift-tipping, solid waste, tricycle truck, kinematic design

\section{INTRODUCTION}

Waste management in developing countries has been a major challenge for municipalities. The municipal waste management in Accra, for example, is discriminatory between the urban poor and the rich (Boadi and Kuitunen, 2003). The municipalities usually sub contract the waste collection components of the management system. The challenges of the waste collection due to improper planning of communities lead to the introduction and use of small tricycle truck. The use of these small trucks in solid waste collection is increasingly becoming popular and very instrumental in waste management chain in developing countries. However, the mode of operation of these small trucks are very much limited to dumping the waste onto the ground or floor to be collected later into collection bin that are made available at community dumping sites. A close look at the mode of operation of these small tricycle truck revealed that its use is cumbersome and involves much labour. Fig. 1 is an illustration of the current mode of operation of the waste collection truck. The waste is initially dump on the ground for it to be collected and put into the disposal container available. This system of operation made the waste collection method unhygienic and exposed the operator to some kind of health hazard.

This paper presents a kinematic design of a mechanism that could aid the operation of the small solid waste collection trucks. Fig. 2 is an illustration of the operational concept of the truck with proposed mechanism. 


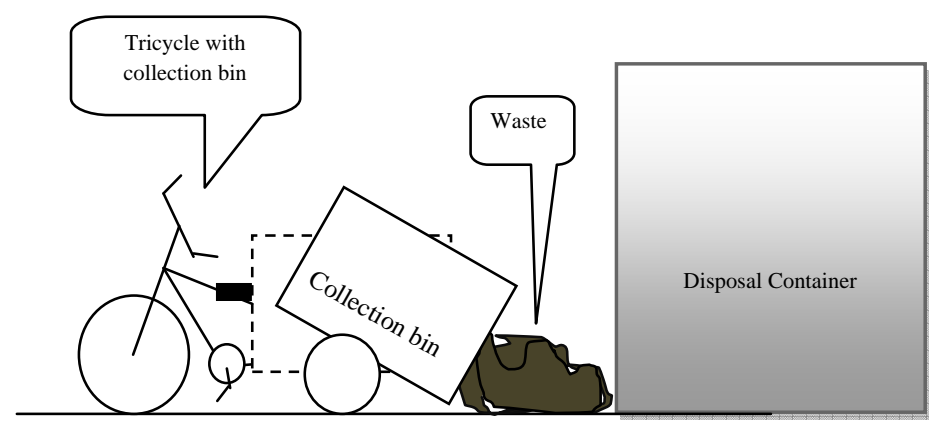

Fig. 1: Illustration of current solid waste truck operation

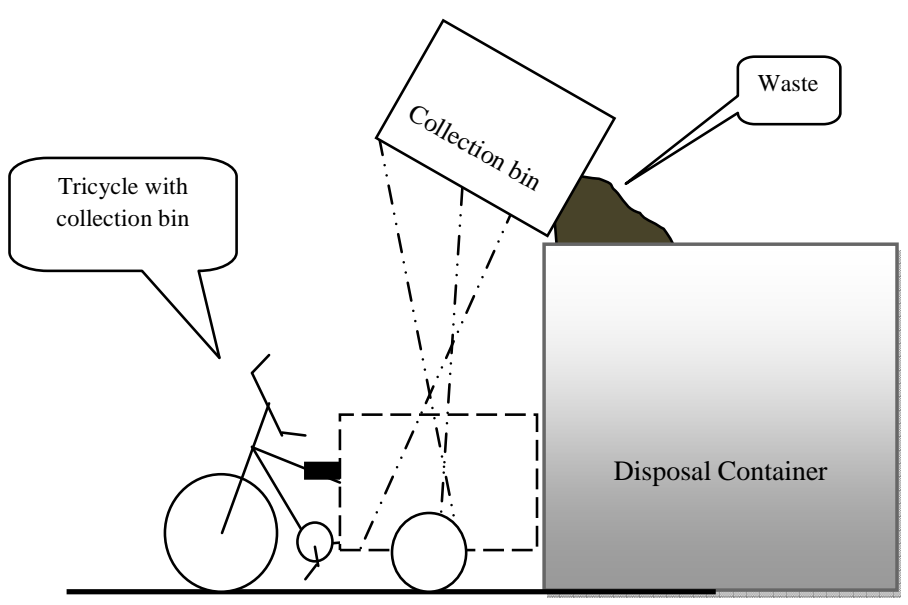

Fig. 2: Illustration of operational concept with lift-tipping mechanism

In operation, the mechanism is expected to lift to a desired height and tilt the bin in order to empty it into available waste container directly. Thus, desired output or performance of the mechanism is of two fold (1) lifting to a desired height and (2) tilting through some desired angle. The actual requirement to attain the desired output is dependent on the available facility used by the waste collection company (that is, the height of receiving container). The second desired output is mainly dependent on physical properties of the solid waste being handled. Glancey and Hoffman (1996) gave the maximum friction coefficient of Municipal Solid 
waste (MSW) and poultry manure with wood surface as 0.75 . This is equivalent to friction angle of $36.89^{\circ}$ which is the minimum tilt angle desired. As such, considering these, the system should tilt through angle more than $36.98^{\circ}$.

\section{SYSTEM DESIGN AND METHOD}

Qualitative method of system synthesis is used for the development of the mechanism for the desired output. The proposed mechanism is made of linkages consisting of five bars as illustrated in Fig. 3 such that " 1 " is the frame; ' 2 ' is the lifting bar; ' 3 ' is the lifting support bar; ' 4 ' is tipping arm and ' 5 ' is the bin. ' 6 ' is a slider. The lifting bar and lifting support bar are connected at the point ' $\mathrm{C}$ '. The tipping arm is connected to the lifting support bar at point ' $D$ '. The tipping arm and the lifting bar are connected to the bin at point ' $E$ ' and ' $F$ ' respectively. The lifting support bar is also connected to the frame or ground at point ' $\mathrm{B}$ '. The lifting bar is connected to the ground at point ' $A$ ' and is allowed to move or slide horizontally. All joint are pin joints but joint ' $A$ ' which is sliding joint.

Gruebler formula is used to test for mobility or degree of freedom of the system. Gruebler condition of a kinematic chain is given as (Norton, 1999)

$$
M=3 L-2 J-2 G
$$

Where $M$ is the mobility or the degree of freedom of the linkage, $L$ is number of links, $J$ is the number of joints and $G$ is the number of grounded links.

From Fig. 3, number of links, $L=5$, number of joints consist of 5 full joints and 1 half joint (sliding joint), hence $J=51 / 2$, number of grounded links, $G=1$. Therefore, the mobility $M$ is One (1). Hence, the system has one (1) degree of freedom meaning that a single input is required to achieve the result of lifting and tilting of link 5 which represents the bin. The degree of freedom being positive is an indica- tion that the system is truly a mechanism as expected.

\section{SYSTEM KINEMATICS AND SIMULA- TION}

The mechanism as one degree of freedom system requires one input parameter identified as actuated displacement, $L_{l}$ (Fig. 4). The two output parameters are lift height, $L_{2}$ and tilt angle, $\theta$. The tilt angle is seen to be influenced by two parameters, $L_{3}$ and $L_{4}$, (Fig. 4). Lifting (link 2) and lifting support (link 3) bars of the mechanism are modelled based on a unit length using Solid Edge software. The actuation of the mechanism could be achieved by employing power screw, hydraulic or pneumatic actuators, rack and pinion combination or any other possible actuating system.

\section{RESULTS AND DISCUSSION}

The simulation results of the mechanism are presented as in Fig. 5 and Fig. 6. According to Fig. 5, the lift height, $L_{2}$ increases with increase in actuated displacement, $L_{l}$. The tilt angle, from Fig. 6, increases with increase in $L_{l}$. Influence of the $L_{3}$ and $L_{4}$ on the tilt angle is such that for $L_{3}<L_{4}$, the tilt angle is generally lower than when $L_{3}>L_{4}$. The lifting height desirable is dependent on facilities available. The achievable height of $70 \%$ of the lifting bar length should be good enough. Tilting angle of more than $40^{\circ}$ with $L_{3}=L_{4}$ achieved will overcome the frictional resistance between the municipal solid waste and the surface material of the collection bin.

A particular tricycle in use by one of the waste collection companies in Ghana is modelled with the mechanism as illustrated in Fig. 7. Fig. 8 shows the mechanism in operation, lift-tilt position. This illustration indicates the operational capability of the system. Using the dimensions of the existing system for the model, the lifting bar is $1.20 \mathrm{~m}$ and tilting bar dimension is taken to be $0.50 \mathrm{~m}$. The simulation of the model with these parameters results in a lifting height of $0.75 \mathrm{~m}$. The total height achieved is therefore $1.15 \mathrm{~m}$ from the ground 
138 Fiagbe et al.

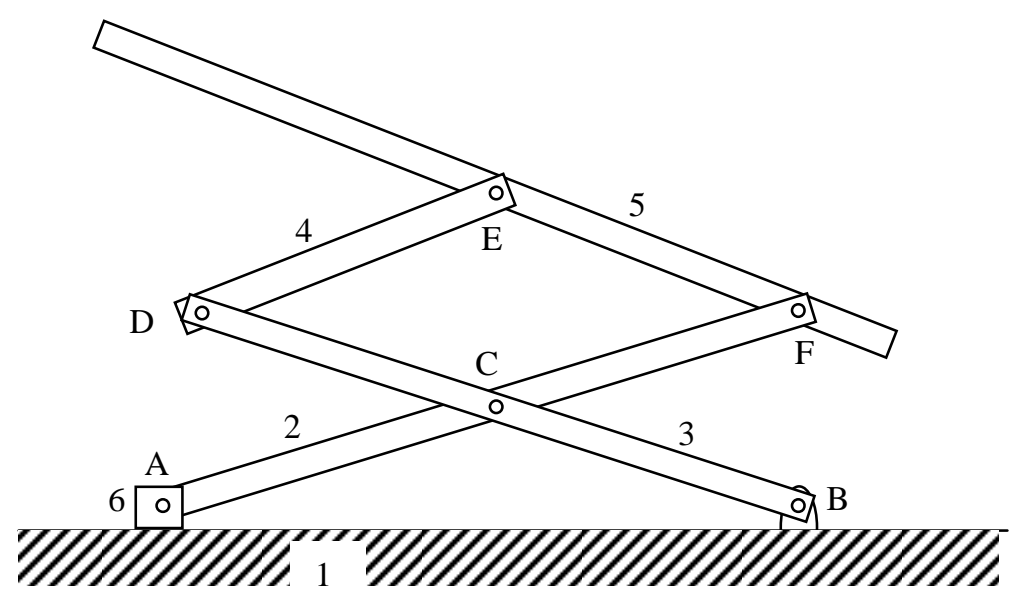

Fig. 3 : Schematic of kinematic linkage chain

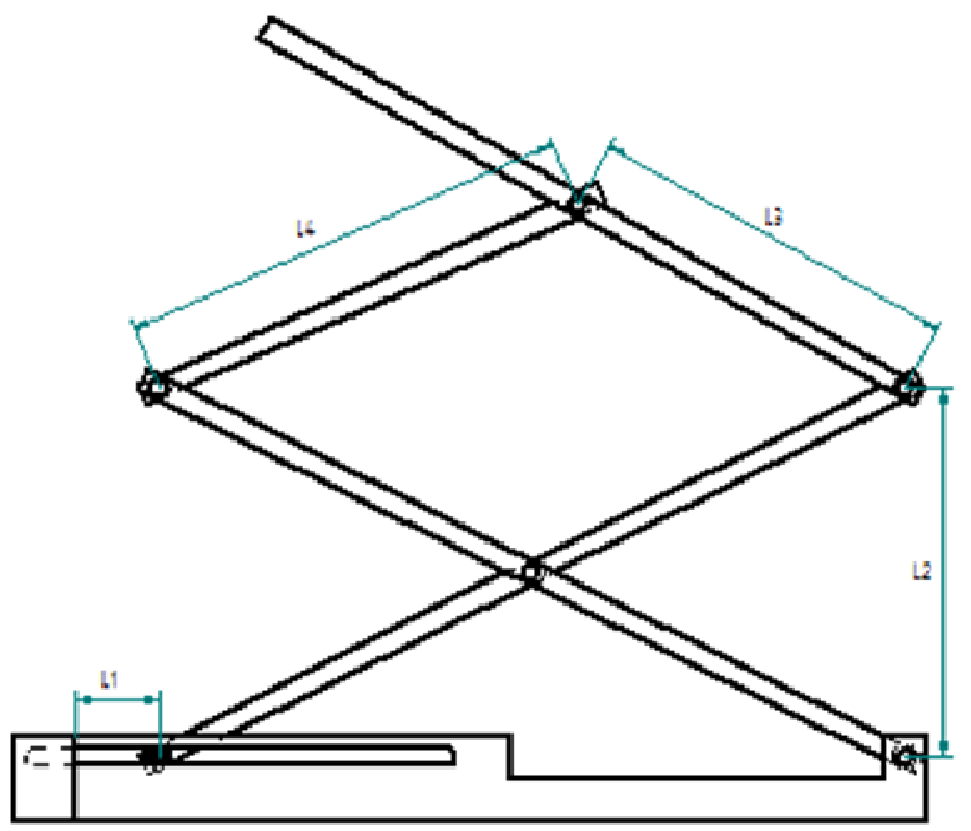

Fig. 4 : Illustration of system input and output parameters 


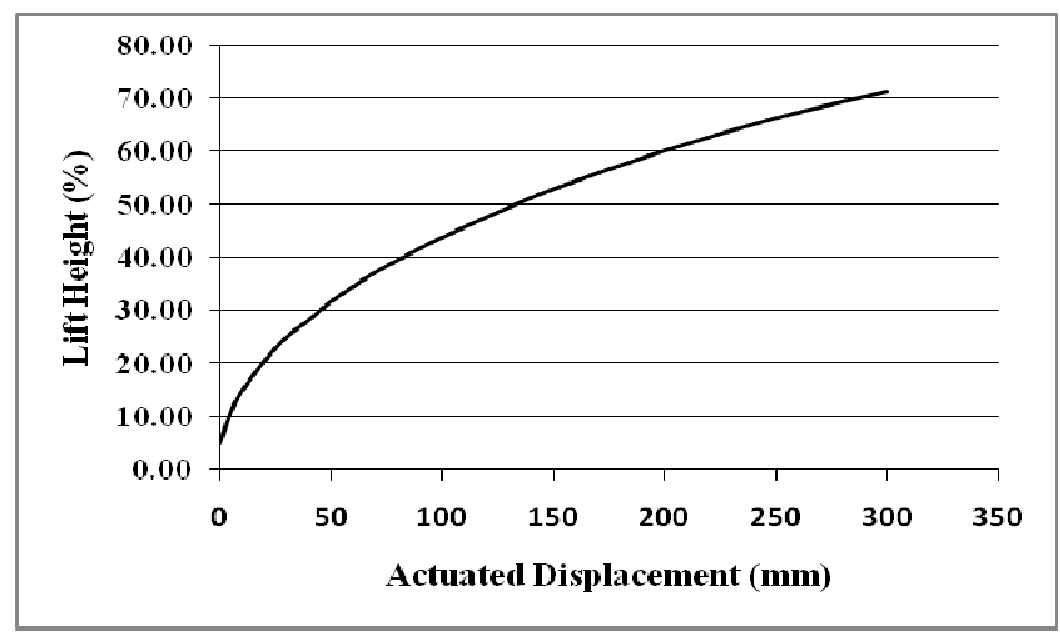

Fig. 5: Lift height with actuated displacement

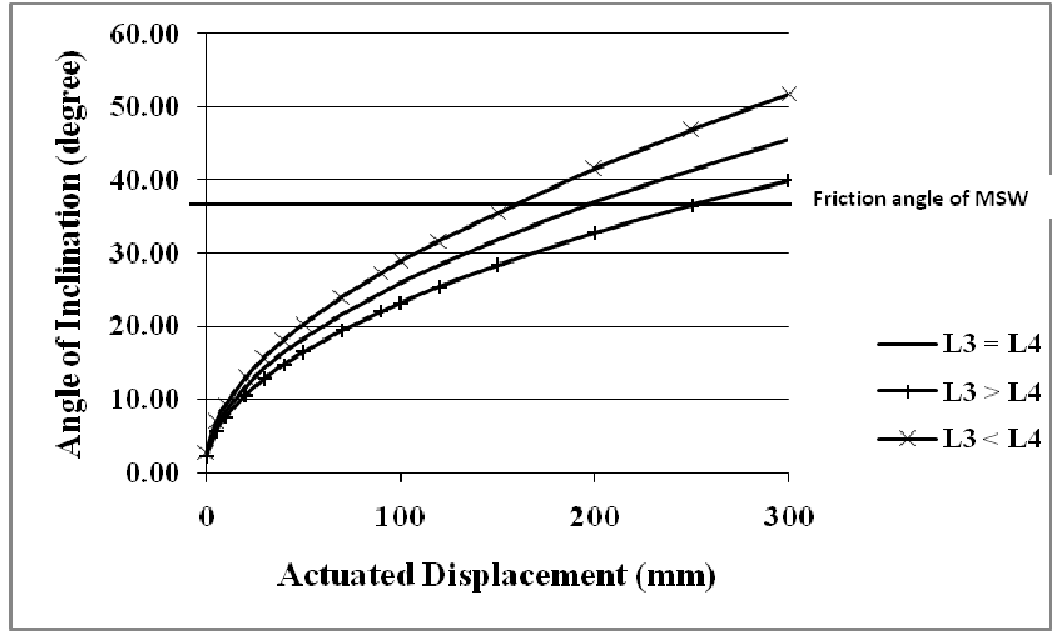

Fig. 6 : Tilt angle with actuated displacement

since the system is $0.40 \mathrm{~m}$ from the ground. A tilt angle of $38^{\circ}$ was achieved. The results of the model simulation are in line with the initial normalised or dimensionless simulation as well as the original operational concept.

\section{CONCLUSION}

Kinematic design of a five bar mechanism with mobility of one has been undertaken. The mechanism developed would enable the tricycle truck to directly dump its content into the disposal container at the receiving site. The system would lift to a desired height and tilt through some desired angle.

The result of the simulated system with norma- 


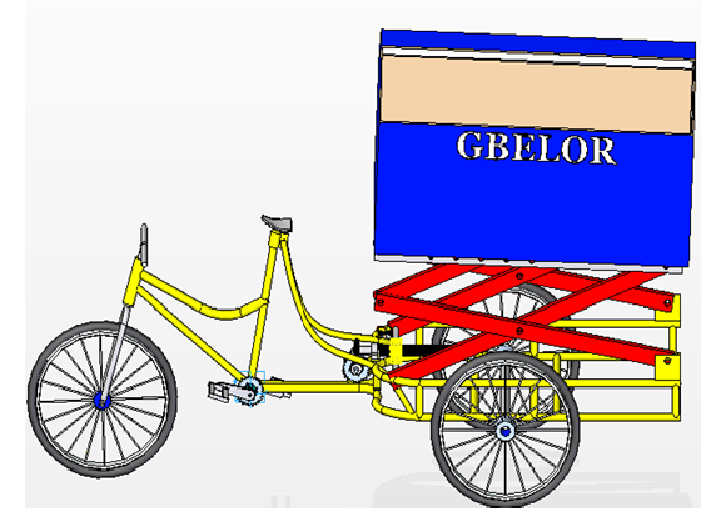

Fig. 7: Model of existing tricycle with mechanism

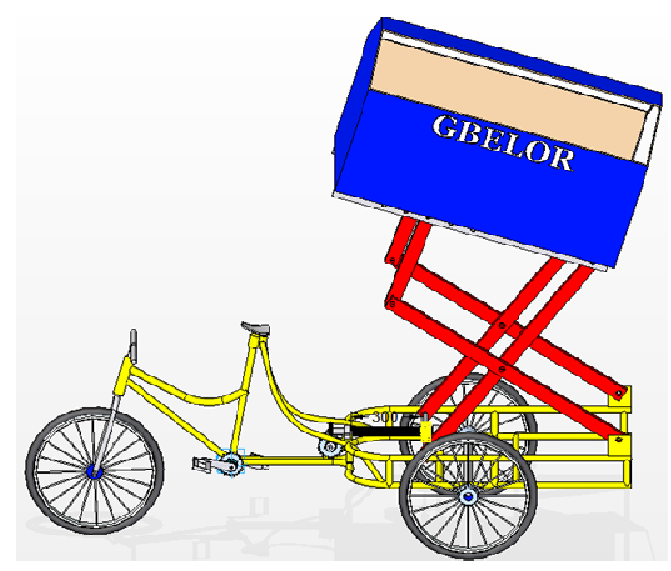

Fig. 8: Model of existing tricycle with mechanism in place as lift-tilt position

lised or dimensionless parameters shows that the mechanism could lift to the height of $70 \%$ of lifting bar and tilt through an angle more than $40^{\circ}$ which is above $36.89^{\circ}$ (friction angle of municipal solid waste with wooden surface). Simulated model with existing sample system parameters confirmed the normalised results with achievable height of $1.15 \mathrm{~m}$ and tilt angle of $38^{\circ}$. The height of $1.15 \mathrm{~m}$ satisfies most required disposal heights. With the requirement of single input information, the actuation of the system could be achieved by employing power screw, hydraulic or pneumatic actuators, rack and pinion or combination of any other possi- 
Kinematic design of lift-tipping mechanism... 141

ible actuating system depending on the level of complexity desire. With the implementation of the mechanism with the small solid waste collection trucks in use in developing countries, good sanitary environment would be created at the dumping site of these small trucks. A further work is to build a prototype for various levels of operational studies.

\section{REFERENCES}

Adelstein, B. D., Ho, P. and Kazerooni, H. (1996). "Kinematic Design of a three degree of freedom parallel hand controller mechanism", Proceedings of the ASME Dynamic Systems and Control Division, DSC. 58: 539-546.

Artobolesky, I. I. (1976). "Mechanisms in modern Engineering Design", Vol. 2, Mir Publishers, Moscow.
Boadi, K. O. and Kuitanen, M. (2003). "Municipal Solid Waste Management in Accra Metropolitan Area, Ghana", the Environmentalist, 23: 211-218.

Dixon, N. and Jones, D. R. V. (2005). "Engineering Properties of Municipal solid waste", Geotextiles and Geomembranes 23: 206-233.

Glancey, J. L and Hoffman, S. C. (1996). "Physical Properties of Solid waste Materials", Applied Engineering in Agriculture by American Society of Agriculture Engineering. 12(4): 441-446.

Norton, R. L. (1999). "Design of Machinery: An introduction to the synthesis and Analysis of Mechanisms and Machines", $2^{\text {nd }}$ Edition, WCB/McGraw-Hill. 